\title{
Perceived Discrimination as a Threat to the Mental Health of Chinese International Students in Australia
}

\section{OPEN ACCESS \\ Edited by: \\ Robyn M. Gillies, \\ The University of Queensland, \\ Australia \\ Reviewed by: \\ Zhihong Ren, \\ Central China Normal University, \\ China \\ Noelia Morales-Romo, University of Salamanca, Spain Natalia Gomes, \\ Instituto Politécnico da Guarda, \\ Portugal \\ Valentina Guerrini, \\ University of Florence, Italy \\ Francisco Javier Lena-Acebo, \\ University of Cantabria, Spain \\ *Correspondence: \\ Elaine Chapman \\ elaine.chapman@uwa.edu.au \\ 'ORCID: \\ Jian Zhao \\ orcid.org/0000-0001-8013-6554 Elaine Chapman orcid.org/0000-0001-5861-1179 \\ Stephen Houghton orcid.org/0000-0002-6744-1068 \\ David Lawrence \\ orcid.org/0000-0003-4700-1425}

Specialty section:

This article was submitted to

Higher Education,

a section of the journal

Frontiers in Education

Received: 17 June 2021 Accepted: 11 January 2022 Published: 04 February 2022

Citation:

Zhao J, Chapman E, Houghton S and Lawrence D (2022) Perceived

Discrimination as a Threat to the Mental Health of Chinese International

Students in Australia.

Front. Educ. 7:726614.

doi: 10.3389/feduc.2022.726614

\author{
Jian Zhao ${ }^{\dagger}$, Elaine Chapman ${ }^{\star}$, Stephen Houghton ${ }^{\dagger}$ and David Lawrence ${ }^{\dagger}$ \\ Graduate School of Education, University of Western Australia, Perth, WA, Australia
}

In this study, a brief instrument (the Mental Health Change Indicator Scale, MHCIS) was developed for use in assessing the impact of a negative event on mental health. The instrument was then used to compare the reported impact of the COVID-19 pandemic on the mental health of Chinese university students studying either in China $(n=734)$ or Australia $(n=108)$. Perceived discrimination and social support were also evaluated as possible mediators of the relationship between country of residence (Australia vs China), and mental health impact. Results suggested that the 10-item MHCIS was unidimensional and psychometrically sound, and that the pandemic had a significantly $(p<0.001)$ more negative impact on the mental health of Chinese students studying in Australia than on those studying in China. Perceived discrimination was identified as a key mediating factor in this relationship. Possible implications for higher education institutions in Australia are discussed.

Keywords: mental health, perceived discrimination, perceived social support, COVID-19, international education, Chinese international students

\section{INTRODUCTION}

The mental health of university students is now a key priority for the Australian Higher Education (HE) sector. Studies have suggested that these students often experience increased levels of anxiety and depression after entering university (Bewick et al., 2010; Barrable et al., 2018), and may continue to experience various psychological difficulties over the course of their $\mathrm{HE}$ enrolments due to factors such as academic pressures and loneliness (Browne et al., 2017). In October 2021, Universities Australia, a consortium of 39 Australian universities, launched the Real Talk Framework to increase the focus of all institutions on the issue of mental health for both staff and students in Australian universities. This framework is designed to ensure that university staff are able to identify changes in staff and student behaviours that may signal mental health problems, and provide support at appropriate junctures for those in need.

HE students' mental health has received particular attention in recent times against the backdrop created by the COVID-19 pandemic. Various authors have highlighted the potential impact of the pandemic on mental health, due to the negative effects it has had on individuals' work, education, travel, recreational activities, and financial status (Charlton, 2020; Daniel, 2020; World Health Organisation: WHO, 2021). Attendant periods of lockdown, social isolation, and general disruption have also emerged as serious risk factors for adverse mental health outcomes, including anxiety, stress and depression (Chang et al., 2020; Horigian et al., 2020). While all individuals are vulnerable to such effects, previous research has indicated that university students may be particularly vulnerable to developing mental health issues in times of stress, as compared with general populations (van Zyl et al., 2021). 
A significant body of research has appeared with respect to university students' mental health during COVID-19. This research has been conducted in various countries including China (Li HY. et al., 2020; Li Y. et al., 2020; Chang et al., 2020; Ma et al., 2020; Wang and Zhao, 2020; Fu et al., 2021), the United States (US) (Horigian et al., 2020; Huckins et al., 2020; Kecojevic, 2020; William et al., 2021), the Netherlands (Llewellyn et al., 2021), and France (Wathelet et al., 2020). All of these studies have confirmed the potential negative mental health effects of the pandemic for university students in particular. Given this, universities may benefit from monitoring students' mental health during future periods of crisis.

One impediment to the ongoing monitoring of students' mental health in such situations is that there is a paucity of suitable instruments for use in such endeavours. Various instruments are available to measure mental health or/and well-being in general, but none make specific reference to changes in the mental health status of individuals in response to a specific situation. For example, the General Anxiety Disorder-7 (GAD-7) questionnaire by Spitzer et al. (2006); the Self-Rating Depression Scale (SDS; Zung, 1965); the Patient Health Questionnaire (PHQ-9; Kroenke and Spitzer, 2002); the Self-Rating Anxiety Scale (SAS; Zung, 1971); and the Depression, Anxiety and Stress Scales (DASS-42, DASS-21) (Lovibond and Lovibond, 1993, 1995; Osman et al., 2012) all focus on aspects of mental health in a given time period, rather than on mental health responses to specific events. Given that these instruments focus primarily on longer-term mental health status, and also their length, they are likely to be less suitable for use as brief, ongoing monitoring tools to test for responses to specific adverse events in large groups such as student populations.

The first aim of the present research was to develop a selfreport instrument that measures changes in relevant indicators of individuals' mental health while dealing with a negative event. The 10-item MHCIS developed in this study has two main advantages over existing measures available. First, it is relatively brief and would be easy to understand for people of most education levels. Second, it measures mental health changes in response to a given event, rather than measuring general mental health 'states' over specified periods, as existing scales do. In the study, an evaluation of this instrument was conducted with two groups of Chinese students in the aftermath of the COVID-19 pandemic outbreak.

The previous research cited which has explored students' reactions to the pandemic has also neglected potentially important moderating factors in these effects. In particular, these studies did not focus upon whether the students were studying in their home countries or abroad during the crisis. This is potentially a significant factor. For students studying abroad, the pandemic may have increased known risk factors for the development of mental health problems. One the most commonly cited factors is a lack of social support, defined by Cohen (2004, p.676) as the "provision of psychological and material resources intended to benefit an individual's ability to cope with stress". Perceived social support refers to the social support that an individual perceives is available during times of need from friends, family members and others (Ioannou et al., 2019).
It is well documented that perceived social support is essential for maintaining mental health, and that, conversely, a lack of social support may lead to harmful mental health consequences (Ioannou et al., 2019; Muñoz-Bermejo et al., 2020; Xu et al., 2020). For example, Ioannou et al. (2019) reported that perceived social support from family and friends was significantly associated with lower depressive symptoms among a group of young adults in Cyprus $(n=344)$. Very recently, Xu et al. (2020) conducted a longitudinal study to explore the association between loneliness, perceived social support, and anxiety among a group of Chinese people ( $n=222$ ) before the COVID-19 outbreak, and at the peak and decline stages of the COVID-19 pandemic. Results indicated that perceived social support provides protection for lonely people both in their daily lives and during unexpected crises such as the recent pandemic.

A second factor that has been cited as a potentially important risk factor for mental health is discrimination, which is defined as "unfair or prejudicial treatment of people and groups based on characteristics such as race, gender, age or sexual orientation" (American Psychological Association, 2019, para.1). The current study focused upon racially-based discrimination, which is a particular type of discrimination targeting people of different colours, descents, ethnicities, and or nationalities (Australian Human Rights Commission, 2021). While definitions of discrimination from a legal standpoint refer primarily to the behaviour of perpetrators, from a mental health standpoint, it is the perceptions of the victims that are critical. As a result, most instruments to assess discrimination used in the mental health literature measure perceived discrimination from the victim's perspective (Paradies, 2006; Blodorn et al., 2016).

Previous studies have shown that discrimination is positively associated with indicators of mental health such as depression (Schulz et al., 2006; Pascoe \& Richman, 2009; Lewis et al., 2014; Assari et al., 2017). Noh et al. (2007) interviewed 180 adult Korean immigrants who were living in Toronto, Canada to investigate overt and subtle forms of racial discrimination on their mental health-positive affect and depressive symptoms. They found that perceived racial discrimination was associated with both decreased positive affect and increased depressive symptomatology among Korean immigrants in Toronto. In another study, Ward et al. (2019) examined the association between perceived discrimination and depressive symptoms among a group of Mexican-origin adults $(n=629)$ in the United States. They found that participants who had experienced discrimination were more likely to report depressive symptomatology than did those who never or rarely experienced discrimination.

Studying abroad has been found to impact both of these factors for university students. For example, international students have been reported to feel a loss of social support as they leave their families and familiar home environments (Hechanova-Alampay et al., 2002; Yeh and Inose, 2003; Sawir et al., 2008). They have also been reported to confront a higher level of discrimination than domestic students while studying in their host countries (e.g., Poyrazli and Lopez, 2007; Wei et al., 2015; Tsai and Wei, 2018; Sun et al., 2021). Given the critical role these two factors play in mental health as summarised above, it is 
TABLE 1 | Demographic information of participants.

\begin{tabular}{|c|c|c|c|c|c|c|c|c|c|}
\hline \multirow[t]{2}{*}{ Characteristics } & \multirow[t]{2}{*}{ Response } & \multicolumn{2}{|c|}{ All CDS $(n=734)$} & \multicolumn{2}{|c|}{$\begin{array}{c}\text { Random split } \\
\text { sample group A: } \\
\text { CDS }(n=367)\end{array}$} & \multicolumn{2}{|c|}{$\begin{array}{l}\text { Random split } \\
\text { sample group B: } \\
\text { CDS }(n=367)\end{array}$} & \multicolumn{2}{|c|}{$\begin{array}{c}\text { Group C: CIS } \\
(n=108)\end{array}$} \\
\hline & & $\mathbf{n}$ & $\%$ & $\mathbf{n}$ & $\%$ & $\mathbf{n}$ & $\%$ & $\mathbf{n}$ & $\%$ \\
\hline \multirow[t]{4}{*}{ Sex } & Female & 395 & 53.8 & 195 & 53.1 & 200 & 54.5 & 66 & 61.1 \\
\hline & Male & 338 & 46.0 & 172 & 46.9 & 166 & 45.2 & 42 & 38.9 \\
\hline & Others & 1 & 0.1 & 0 & 0 & 1 & 0.3 & 0 & 0 \\
\hline & Missing & 0 & 0 & 0 & 0 & 0 & 0 & 0 & 0 \\
\hline \multirow[t]{3}{*}{ Marital Status } & Married/In a relationship & 184 & 25.1 & 99 & 27.0 & 85 & 23.2 & 41 & 38.0 \\
\hline & Single/Separated/Divorced & 533 & 72.6 & 264 & 71.9 & 269 & 73.3 & 66 & 61.1 \\
\hline & Missing & 17 & 2.3 & 4 & 1.1 & 13 & 3.5 & 1 & 0.9 \\
\hline
\end{tabular}

possible that international students will experience a greater negative impact on mental health in response to events such as the COVID-19 pandemic. Studies conducted prior to the pandemic support this assertion. For example, a meta-analysis by Bender et al. (2019) underscored the critical role played by social support in international students' psychological adjustment. Findings of this kind suggest an urgent need for further investigation into how the COVID-19 pandemic has affected the mental health of this vulnerable group.

The second goal of the present research was thus to use the newly developed MHCIS instrument, together with other established mental health scales, and to compare the mental health status of two groups of Chinese university students (those studying in China and in Australia) in the wake of the COVID-19 pandemic. The potential mediating effects of perceived social support and perceived discrimination in the relationship between country of residence (Australia vs China), and students' mental health and well-being status in the pandemic setting were also evaluated.

\section{METHOD}

\subsection{Participants}

Following the removal of incomplete responses, the final sample for the study consisted of 842 students, including 734 enrolled in Chinese universities and 108 students enrolled in Australian universities. The first group was then randomly split into two halves for the internal structure validity analysis. Each split-half (Groups A and B) comprised 367 cases. Group C included the 108 students who were studying in Australian universities. Demographic information is shown in Table $\mathbf{1 .}$

\subsection{Instruments}

The MHCIS is a 10-item self-report measure developed by the first two authors that was designed to measure changes in one's mental health while dealing with a negative life event. All items were carefully generated or developed according to existing research literature focusing on mental health (Barlow, 1991; American Psychiatric Association, 2013; Downs et al., 2013; Lee, 2020). Each item in the MHCIS captured changes in one specific negative indicator of mental health while facing a negative life event (in this study, COVID-19). Collectively, the MHCIS referred to cognitive, emotional, physiological, and behavioural changes that could signal a negative shift in mental health in response to such an event. Each item was rated on a 5-point scale, ranging from 1 (never) to 5 (always), and with higher scores indicating greater change in mental health. The items in the MHCIS were developed first in English and then translated into Chinese to allow participants in this study to complete it in their first language. The 10 items within the instrument (in both versions) are listed in Table 2.

Two established instruments (the World Health OrganisationFive Well-Being Index or WHO-5 and the 12-item Depression, Anxiety and Stress Scale or DASS-12) were used in this study to further validate the MHCIS. These two instruments were used specifically to evaluate the MHCIS in terms of how its scores correlate with theoretically correlated variables (Messick, 1989; Messick, 1995), as well as to provide additional outcome variables in the path analysis in the second stage of the research.

The WHO-5 is one of the most widely used instruments to measure one's subjective mental well-being, which was first presented in 1998 by the World Health Organization (1988). It comprises five items, in which respondents are required to rate their wellbeing levels on a six-point Likert scale ranging from 0 (at no time) to 5 (all of the time). The raw score is calculated by adding up the scores of all five answers, ranging from 0 to 25 , with higher scores indicating better well-being (e.g., "I have felt cheerful in good spirits"). The WHO-5 has been demonstrated to exhibit good psychometric properties in many studies with different populations such as college students (Downs, 2017), depressed patients (Krieger et al., 2013), and adults in the United Kingdom during initial lockdown of COVID-19 pandemic (White and Van Der Boor, 2020). Given its excellent psychometric properties, this instrument was chosen as a measure of positive mental health in the current study.

The DASS-12 was used in this study to measure individuals' negative emotional states. The DASS-12 is a shorter version of the DASS-21, which is a self-report questionnaire to measure the negative emotional states of depression, anxiety and stress developed by Lovibond and Lovibond (1995). The DASS-12 consists of three scales, each of which includes four items (e.g., I found it hard to wind down.). Respondents are asked to respond to each item on a scale from 0 (did not apply to me at all) to 3 (applied to me very much). Scores for each scale are added, with higher scores indicating more serious conditions. The DASS-12 
TABLE 2 | Statements, communalities and factor loadings for the MHCIS items.

\begin{tabular}{|c|c|c|c|c|c|}
\hline \multirow[t]{2}{*}{ Item label } & \multirow{2}{*}{$\begin{array}{c}\text { Item number and statement } \\
\text { Stem prompt: You may have noticed changes in yourself since realizing the seriousness } \\
\text { of the COVID-19 pandemic. Which, if any, of the following changes have you noticed in } \\
\text { yourself during this period? }\end{array}$} & \multicolumn{2}{|c|}{ Group a data $(n=367)$} & \multicolumn{2}{|c|}{ Group C data $(n=108)$} \\
\hline & & $h^{2}$ & $\begin{array}{c}\text { Component } \\
\text { Matrix }\end{array}$ & $h^{2}$ & $\begin{array}{c}\text { Component } \\
\text { Matrix }\end{array}$ \\
\hline MHCIS_1 & Finding my thinking distracted a lot of the time & 0.65 & 0.89 & 0.65 & 0.89 \\
\hline MHCIS_2 & Feeling generally tense, stressed or worried & 0.64 & 0.88 & 0.64 & 0.88 \\
\hline MHCIS_3 & Feeling a sense of loss or grief & 0.80 & 0.86 & 0.80 & 0.86 \\
\hline MHCIS_4 & Feeling sad or hopeless & 0.74 & 0.84 & 0.74 & 0.84 \\
\hline MHCIS_5 & Feeling agitated or 'on edge' & 0.71 & 0.83 & 0.71 & 0.83 \\
\hline MHCIS_6 & Feeling exhausted and tired for no good reason & 0.68 & 0.83 & 0.68 & 0.83 \\
\hline MHCIS_7 & Losing interest in things I normally like to do & 0.65 & 0.81 & 0.65 & 0.81 \\
\hline MHCIS_8 & Am quieter or more withdrawn from friends/family & 0.66 & 0.81 & 0.66 & 0.81 \\
\hline MHCIS_9 & Overreacting to minor issues more often than usual & 0.77 & 0.80 & 0.77 & 0.80 \\
\hline MHCIS_10 & Having outbursts of anger and hostility & 0.70 & 0.80 & 0.70 & 0.80 \\
\hline
\end{tabular}

Extraction Method: Principal Component Analysis.

TABLE 3 | Perceived discrimination and perceived social support scale statements.

\begin{tabular}{|c|c|c|}
\hline Instrument & Item & Statement \\
\hline \multirow[t]{4}{*}{ Perceived Discrimination Scale Statements } & 1 & I have felt more unsafe since the outbreak due to increased discrimination against Chinese people \\
\hline & 2 & Since the outbreak, I have felt that I am being treated differently from others because I am Chinese \\
\hline & 3 & I have personally been insulted or harassed because of my Chinese background more often since the outbreak \\
\hline & 4 & I have grown more afraid due to reports of increased discrimination against Chinese people since the outbreak \\
\hline \multirow[t]{4}{*}{ Perceived Social Support Scale Statements } & 1 & $\begin{array}{l}\text { I often feel that there would be no-one around to help me if I got into trouble vs There are always people that I can call } \\
\text { upon to help me when I need it }\end{array}$ \\
\hline & 2 & $\begin{array}{l}\text { My social network is not strong (e.g. not close to anyone) vs I have a strong social network (e.g., very close connection } \\
\text { with family or friends) }\end{array}$ \\
\hline & 3 & I have no one with whom to share my emotions vs I always have someone with whom I can share my emotions \\
\hline & 4 & I have no one to turn to when I want to talk vs When I want to talk, I always have someone to turn to. \\
\hline
\end{tabular}

has been demonstrated to have sound psychometric properties. For example, Lee et al. (2019) gathered data on both DASS-21 and DASS-12 from 1,000 Korean respondents, and found that a threefactor model demonstrated good fit to the data, with satisfactory Cronbach's a coefficients for both the DASS 21 and 12 (0.93 and 0.90 , respectively). The Cronbach's as for the DASS 12 subscales were a slightly lower $(0.74-0.90)$ than those for DASS 21 , but still satisfied the generally accepted criterion of $>0.70$. In light of these positive attributes, the DASS- 12 was chosen as a measure of negative mental health indicators in the current study.

Four further items were also included to measure increases in students' perceptions of perceived discrimination following the outbreak (the Perceived Discrimination Scale or PDS). All of the items in the PDS are presented in Table 3. These were developed based on existing instruments on perceived discrimination. A principal component analysis (PCA) performed with all participants $(n=842)$ on scores from this scale suggested a unidimensional structure, which accounted for $77.30 \%$ of the total item variance, with a high level of internal consistency $(\alpha=0.90)$.

A second additional scale (The Perceived Social Support Scale or PSSS) was also included to measure the level of social support that students perceived that they had at the time of the pandemic, though this scale made no specific reference to the outbreak itself. Items in the PSSS were designed to measure an individual's perceived social support based on existing instruments (Zimet et al., 1988). The four items in the PSSS are all shown in Table 3. Students respond to each item using a 7-point bipolar statement rating scale (ranging from -3 to 3 ), with higher scores indicating higher level of social support perceived by participants. An overall total score is computed by adding all 4 item scores (ranging from -12 to 12), with higher scores indicating a higher level of perceived social support received. The PCA on these items $(n=842)$ also suggested that it was a single factor scale (which accounted for $77.48 \%$ of the total item variance) with high internal consistency $(\alpha=0.89)$.

\subsection{Data Collection}

Data were collected from 23 August 2020 to 31 December 2020. An online survey created through Qualtrics was disseminated among Chinese students who were enrolled in various Chinese universities across mainland China and Australian universities. An anonymous link to the survey was distributed to prospective participants via WeChat. Electronic consent forms were gained online from participants before they started the survey. All the participants were told that their participation was on a voluntary basis and no special incentives or awards were offered for their participation.

\subsection{Data Analysis}

In the validation of the MHCIS, we first created two random splitsamples within the overall pool of data collected on Chinese 
domestic students (only the data from domestic students was used for this analysis owing to the relatively small sample of Chinese international students that could be obtained for the study). We then conducted an exploratory factor analysis on one split half, and used a confirmatory factor analysis to cross-validate these results based on data from the second split half group. This is a common approach to evaluating the internal structure of new and existing instruments (e.g., Revicki et al., 2014).

Exploratory factor analysis (EFA) is to provide a preliminary analysis of the constructs needed to account for patterns of correlation among measures when little is known about the factorial structure or the dimensionality of an instrument (Fabrigar and Kan, 2018). Confirmatory factor analysis (CFA) is used to evaluate to determine the extent to which specified relationships between observed indicators and underlying latent variables align with empirical observations (Randall and Jung, 2018). Thus, these two approaches provide a complementary perspective on the internal structure of instruments in validation studies.

Cronbach's as and bivariate correlations were also used in the evaluation of the validity of the MHCIS. Analyses of variance (ANOVAs) were also used to explore differences across Chinese students studying domestically and internationally, while path analysis was used to determine whether perceived discrimination and social support were significant mediators of the relationship between country of residence (China vs Australia) and reported impacts of COVID-19 on mental health. Path analysis is used primarily to identify both the direct and the indirect relationships between a predictor and a dependent variable (Menard, 2012).

In this study, IBM SPSS V27 was used to conduct the EFAs, bivariate correlations and ANOVAs, while LISREL V8.80 was used to conduct the CFAs, and path analysis.

\section{RESULTS}

\subsection{Stage 1: Validation of the MHCIS}

The instrument validation for the MHCIS addressed four of the five types of evidence put forward by Messick (1989); Messick (1995) based on his re-conceptualisation of validity. The four types of evidence are related to validity evidence in terms of content, response processes, internal structure, and relations with other variables. The fifth type of evidence that was not addressed was evidence related to the consequences of the instruments' application. The reason that the latter type of validity was not assessed is that to generate this type of evidence, the instrument must be used over a relatively long time period, which fell beyond the scope of the present study.

\subsubsection{Validity Evidence based on Test Content}

All items in the MHCIS were developed based on an extensive review of existing research literature regarding mental health and scales that measured mental health symptoms (Barlow, 1991; American Psychiatric Association, 2013; Downs et al., 2013; Lee, 2020). After being developed by the first two authors, the MHCIS was sent to two experts in the mental health field for their feedback regarding the wording, phrasing and content of the items. Revisions to the wordings were then made based on this feedback, and the adjustments were also applied in the Chinese version.

\subsubsection{Validity Based on Response Processes}

Prior to the official launch of the survey, cognitive interviews were conducted with four Chinese university students. Each participant was asked to read the survey carefully and record the items or questions that were ambiguous or confusing to them. This process was undertaken to ensure that sources of misinterpretation were identified and rectified before the survey was launched. Some further changes and adjustments were made on some items according to the interviewee's feedback to make sure that the survey was clear and understandable to them.

\subsubsection{Validity Evidence based on Internal Structure}

To evaluate the internal structure of the MHCIS, both exploratory factor analysis (EFA) and confirmatory factor analysis (CFA) were performed with data from the 734 CDS who were studying in Chinese universities. The 734 respondents were randomly split into two halves for this analysis. The two halves (Groups A and B) included 367 students each. An EFA was performed on data from the Group A $(n=367)$, while a CFA was performed on data from the Group B $(n=367)$. Cronbach's alphas were also computed for each group to evaluate the internal consistency of the MHCIS. A preliminary data screening analysis was conducted before any analysis was performed, which suggested that the data were suitable for factor analysis (Tabachnick and Fidell, 2013). Specifically, no significant violations were identified pertaining to linearity, normality, factorability, and case-to-item ratio (Hatcher, 1994; Kline, 2016).

An EFA was first conducted with data from Group A using a principal components analysis (PCA) extraction method. Communalities and the component matrix are presented in Table 2. According to Kaiser's criterion (1960), these loadings suggested a one factor solution, which accounted for $69.82 \%$ of the total item variance. The one-component structure was also confirmed by the scree plot and the high internal consistency obtained for the Group A data $(\alpha=0.95)$. To provide further evidence for the one-factor structure, another EFA was performed with a group of CISs who were enrolled in Australian universities (Group C, $n=108$ ). These results further supported the one-factor model, with high communalities and rotated loadings associated with the onefactor solution obtained (see Table 2). The internal consistency of the one-factor solution based on the Group $\mathrm{C}$ data was high $(\alpha=0.95)$.

Based on the one-factor model, a CFA was then performed with data from Group B to cross-validate the results obtained in the Group A EFA. The CFA results further confirmed the onefactor obtained from the EFA. Other fit indices including the ratio of the chi-square statistic to the model degrees of freedom $\left(\chi^{2} / d f=\right.$ $4.20)$, the Non-Normed Fit Index (NNFI = 0.95), the Comparative Fit Index $(\mathrm{CFI}=0.97)$, the Standardized Root Mean Square Residual (SRMR $=0.03)$, the Root Mean Square Error of Approximation (RSMEA $=0.09$ ) all suggested sound 


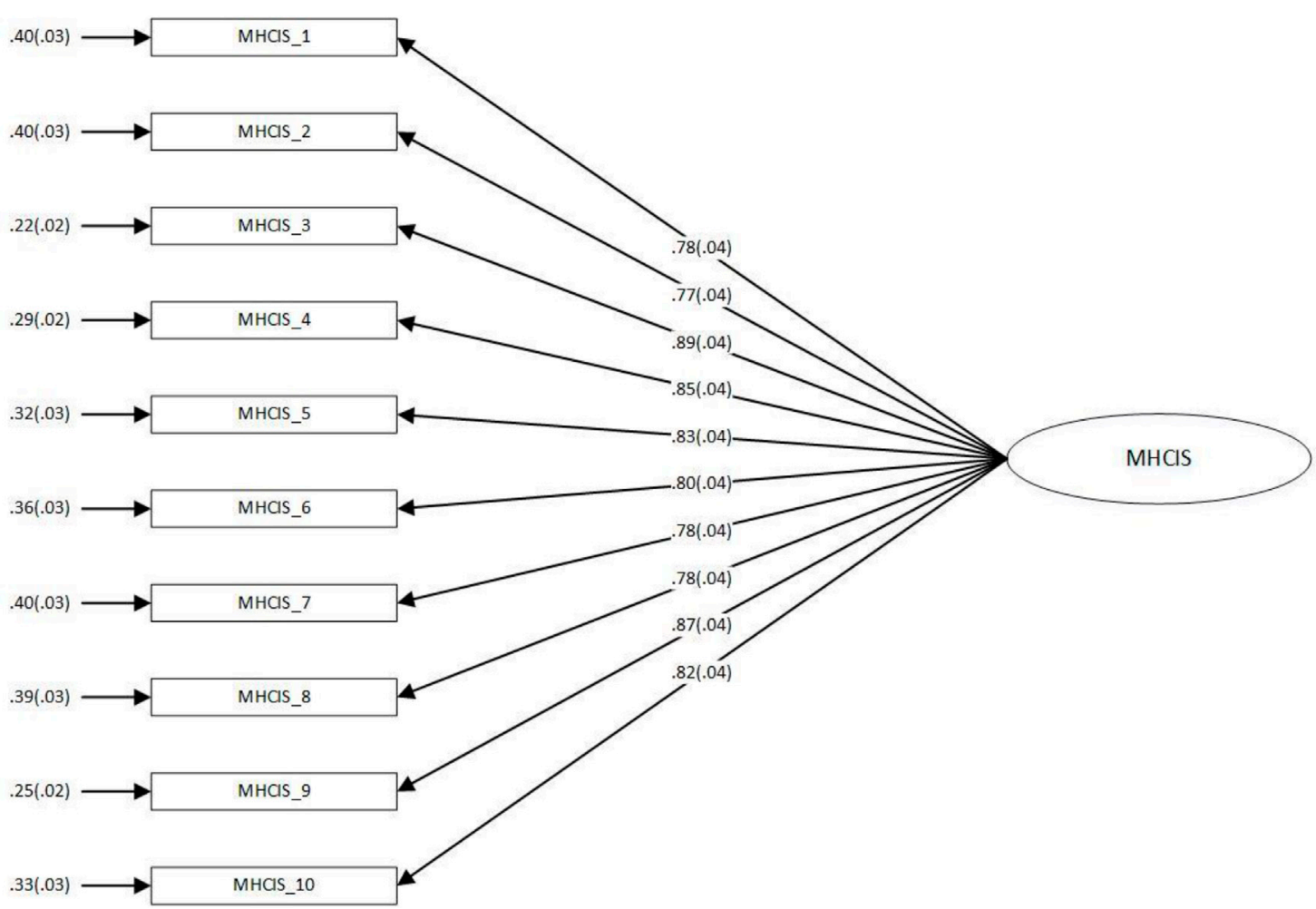

FIGURE 1 | Path diagram for the one-factor model of the MHCIS

TABLE 4 | Correlations between MHCIS, DASS-12, WHO-5, perceived discrimination and social support $(n=842)$.

\begin{tabular}{|c|c|c|c|c|c|c|c|c|c|}
\hline & Mean & $S D$ & MHCIS & DASS_Depression & DASS_Stress & DASS_Anxiety & WHO_Mean & $\begin{array}{c}\text { Perceived } \\
\text { discrimination }\end{array}$ & $\begin{array}{l}\text { Social } \\
\text { support }\end{array}$ \\
\hline MHCIS & 1.83 & 0.88 & 1.00 & $0.60^{\star \star}$ & $0.55^{\star \star}$ & $0.56^{\star \star}$ & $-0.34^{\star \star}$ & $0.37^{\star *}$ & $-0.28^{\star \star}$ \\
\hline DASS_Depression & 1.58 & 0.55 & & 1.00 & $0.75^{\star \star}$ & $0.71^{\star \star}$ & $-0.38^{\star \star}$ & $0.34^{\star \star}$ & $-0.36^{\star \star}$ \\
\hline DASS_Anxiety & 1.49 & 0.51 & & & & 1.00 & $-0.29^{\star \star}$ & $0.29^{\star \star}$ & $-0.25^{\star \star}$ \\
\hline WHO_Mean & 3.11 & 0.09 & & & & & 1.00 & $-0.18^{\star *}$ & $0.33^{\star \star}$ \\
\hline Perceived Discrimination & 1.73 & 0.91 & & & & & & 1.00 & $-0.11^{\star *}$ \\
\hline
\end{tabular}

model fit, and the internal consistency of the one-factor solution based on the Group B data was high $(\alpha=0.95)$. These results further supported the notion that the MHCIS items could all be summarised using a one-factor structure (Hooper et al., 2008; Kline, 2016). Coefficients for the paths between each of the items and their latent factor are shown in Figure 1.

\subsubsection{Validity Evidence based on External Variables}

To provide further validity evidence, the correlations between the total scores of the MHCIS and two well-established instruments (WHO-5 and DASS-12) were explored. The results are shown in Table 4.

All three subscales of DASS-12 were positively correlated with the MHCIS scores $(r=0.60,0.55$, and 0.56 for Depression, Stress and Anxiety, respectively, $p s<0.001)$. WHO-5 was negatively correlated with MHCIS ( $r=-0.34, p<0.001)$. In other words, people who had experienced negative mental health changes as a result of the COVID-19 pandemic were more likely to report higher levels of depression, stress and anxiety, and less likely to enjoy good mental health and well-being. These results provided further evidence to support the concurrent validity of the MHCIS.

\subsection{Stage 2: Mental Health Impact of COVID-19 on Chinese Students Studying Abroad}

A multivariate analysis of variance (MANOVA) was performed to determine whether Chinese students studying in Australia or in China differed significantly on the mental health indicators (WHO-5; DASS Depression, Stress and Anxiety; MHCIS). Prior 
TABLE 5 | Means and Standard Deviations (SDs) and univariate ANOVA results.

\begin{tabular}{|c|c|c|c|c|c|c|c|c|}
\hline \multirow[b]{2}{*}{ Scales/Subscales } & \multicolumn{2}{|c|}{$\operatorname{CDS}(n=734)$} & \multicolumn{2}{|c|}{ CIS $(n=108)$} & \multicolumn{4}{|c|}{ Univariate ANOVAs } \\
\hline & Mean & $S D$ & Mean & $S D$ & $\mathrm{~F}$ & df & Sig. (p) & Partial $\eta^{2}$ \\
\hline WHO-5 & 3.18 & 1.07 & 2.62 & 1.08 & 25.81 & 1 & $<0.001$ & 0.03 \\
\hline DASS-Depression & 1.55 & 0.53 & 1.80 & 0.65 & 19.61 & 1 & $<0.001$ & 0.02 \\
\hline DASS-Stress & 1.79 & 0.59 & 2.15 & 0.73 & 33.14 & 1 & $<0.001$ & 0.04 \\
\hline DASS-Anxiety & 1.48 & 0.50 & 1.56 & 0.60 & 2.47 & 1 & 0.11 & 0.00 \\
\hline $\mathrm{MHCIS}$ & 1.76 & 0.84 & 2.24 & 1.06 & 28.94 & 1 & $<0.001$ & 0.03 \\
\hline
\end{tabular}

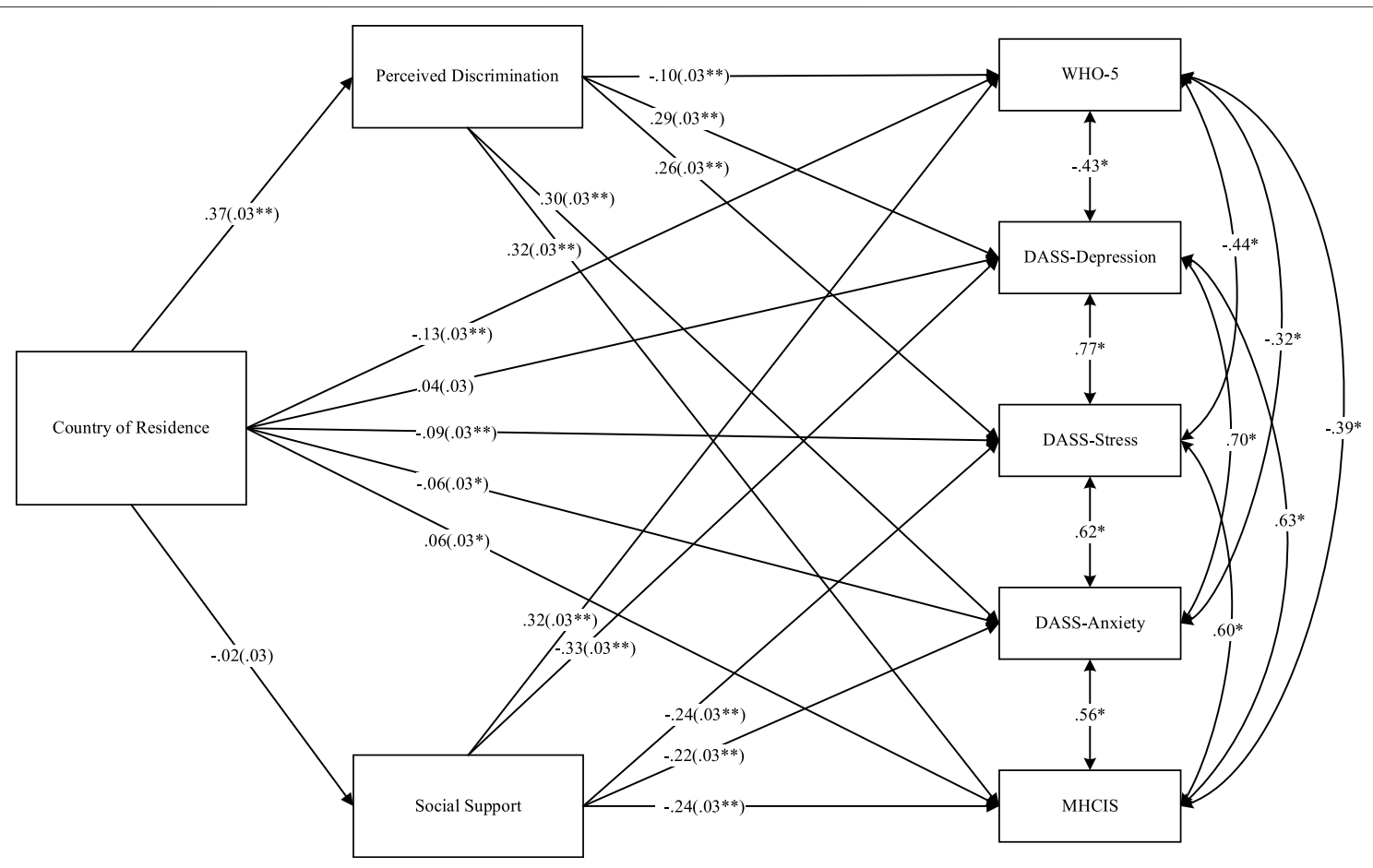

FIGURE 2 | The path analysis model.

to conducting the MANOVA, screening tests were performed with no deviations from relevant assumptions that would substantially affect the $F$ test (Tabachnick and Fidell, 2013).

Means and standard deviations (SDs) are shown in Table 5. Results from the MANOVAs indicated a significant difference on the linear composite dependent variable across the two groups of students, $V=0.07, F(5,833)=11.58, p<0.001$, partial $\eta^{2}=0.07$. Follow-up univariate analyses of variance (ANOVAs) were thus performed to further explore each of these significant multivariate effects across two groups of students. The Holm-Bonferroni correction procedure (see Holm, 1979) was used in evaluating the ANOVA outcomes, to maintain the a level at 0.05 for MANOVA. These indicated a significant $(p<0.05)$ univariate effect on all scales except the DASS Anxiety subscale. In every case, the significant result indicated a less favourable change in status for Chinese students studying in Australia.

To determine whether perceived discrimination and social support were significant mediators of the relationship between country of residence (China vs Australia) and reported impacts of
COVID-19 on mental health, a path analysis was then performed. Correlations between country of residence, and scores on the WHO5, DASS-12, MHCIS, Perceived Discrimination and Social Support measures are shown in Table 4. The path co-efficients associated with all direct effects in the model are presented in Figure 2, while the total indirect effects are shown in Table 6. Hoyle (1995) indicates that $t$-values of between \pm 1.96 and \pm 2.56 are significant at the 0.05 and 0.01 levels, respectively. As indicated in Table 6, all total indirect effects were significant at the 0.01 level. A decomposition of these effects is also shown in Table 6. These outcomes make clear that between 85.25 and $96.19 \%$ of the indirect effect from country of residence to the mental health variables was attributable to perceived discrimination. Only $5.79-14.75 \%$ was attributable to social support.

\section{DISCUSSION}

Overall, the MHCIS was found to be a psychometrically sound instrument for assessing Chinese university students' mental 
TABLE 6 | Indirect effects for variables in path analysis model.

\begin{tabular}{lcc}
\hline Outcome variable & Total indirect effect & $\begin{array}{c}\text { \% Attributable to } \\
\text { Perceived Discrimination } \\
\text { Social Support }\end{array}$ \\
\hline WHO-5 & $p=-0.04(S E=0.02), t=-2.58^{\star \star}$ & 85.25 \\
DASS-Depression & $p=0.11(S E=0.02), t=6.01^{\star \star}$ & 94.21 \\
DASS-Stress & $p=0.10(S E=0.02), t=5.85^{\star \star}$ & 95.25 \\
DASS-Anxiety & $p=0.11(S E=0.02), t=6.48^{\star \star}$ & 96.19 \\
MHCIS & $p=0.12(S E=0.02), t=6.77^{\star \star}$ & 5.79 \\
\end{tabular}

${ }^{*} \mathrm{p}=$ parameter estimate; $\mathrm{SE}$, standard error of the estimate.

health changes in the aftermath of the COVID-19 pandemic outbreak. Given its reliability, validity, cost-effectiveness and simplicity, the MHCIS could potentially be used to monitor the mental health changes of people during stressful periods or function as a primary screening tool to help identify those who have been seriously impacted by negative events such as COVID19 pandemic. Further research could also validate the MHCIS in different cultural contexts with different populations.

The results from Stage 2 of the research indicated that Chinese international students reported experiencing more depression, stress, and mental health changes in response to the COVID-19 outbreak, as well as lower levels of well-being, and than their domestic counterparts. Perceived discrimination was a key mediating variable in this difference. This is aligned with previous studies, which have indicated that perceived discrimination is negatively associated with one's mental health (Noh et al., 2007; Lewis et al., 2014). Somewhat more surprisingly, no significant difference was found between the two groups in terms of their perceived social support. This differs from previous findings which suggest that international students studying in Australian universities (Khawaja and Dempsey, 2008) and in other host countries (Zhang, 2012; Bhochhibhoya et al., 2017) reported feeling that they had less access to social support. It is possible that the increased availability of communication media such as Facetime, Whatsapp, and WeChat have reduced impact of study abroad upon perceived social support. Furthermore, it is possible that this result would be particular to mainland Chinese students, many of who very frequently study far from their homes even when they are enrolled in a Chinese university.

The negative influence of perceived discrimination on mental health suggested by the results is very concerning. Following the spread of COVID-19, discrimination towards Chinese people greatly increased on a worldwide basis. Anti-Chinese/Anti-Asian discrimination and assaults have been reported in various countries (Chen et al., 2020; Devakumar et al., 2020; He et al., 2020; Science Daily, 2020), and on the Website of Human Rights Watch, numerous cases related to Chinese or Asian residents have been reported in different Western countries. In Australia, various cases of racist abuse and attacks (ranging from verbal abuse to physical violence) and vandalism against people of Chinese or Asian descent have been reported across the country since the Covid19 outbreak was first announced. Similar stories have also been reported in the US and the United Kingdom.

In light of the findings of this study, Australian universities need urgently to assess the impact of the outbreak on Chinese international students' mental health and take steps to ensure that these students are protected from increased levels of discrimination during this time. In 2019, Chinese students accounted for more than one third of all international students enrolled in Australian universities (Australian Government, 2019), bringing around 12 billion Australian dollars to the Australian education industry (Hughes, 2021). According to Hurley and Van Dyke (2020), Australia's universities may lose $\$ 19$ billion in total by 2023 because of "the collapse in international student revenue" (p. 3 ), with Bolton (2020) predicting that a loss of some $\$ 12$ billion will be attributable to Chinese students alone.

Possible actions to address this crisis in Australia could take a variety of forms. As an initial step, efforts could be made to increase domestic students' and academics' awareness of international students' experiences and the potential impact of discrimination on mental health. Related workshops and training focused on increasing cultural competence may also be of benefit. For example, the University of Sydney (University of Sydney, 2021) has developed a series of workshops to help participants to gain knowledge of cultural competence, reduce racism, and develop critical self-reflective practices. The University of Queensland (University of Queensland, 2021) also provides similar training to staff to help build inclusive and collaborative environments. Another example is a US-based crosscultural program called "Human Relations in a Multi-cultural Society", which requires students to undertake various tasks such as "self-selected cross-cultural service learning", "group cooperative research and teaching project", and interacting with partners from other cultures" (Sandell and Tupy, 2015, pp. 370-371). Sandell and Tupy compared students' cultural competency before and after participating in this program and found that students showed statistically significant positive gains in their cultural competence after one semester. Taking such steps to reduce cultural misunderstandings and discrimination will be necessary for Australia to build more friendly university study environments and increase the number of Chinese international students it attracts to its shores in the post-COVID recovery period. This will be critical for developing sustainable growth for Australia's international education sector, and aligns well with the Australian Government's Strategy for International Education 2021-2030 (Department of Education, Skills and Employment, 2021).

\section{LIMITATION}

One limitation of the current study is that a far larger number of Chinese students in this study were enrolled in Chinese universities rather than Australian universities. This discrepancy was not 
avoidable, given the Australian border restrictions that have prevented most Chinese international students from entering Australian for the past two years. While the number of Chinese students studying in Australia was still sufficient to ensure the stability of the statistical estimates, further studies would be useful to confirm the generality of the findings reported here. Such research could also shed further light on the nature of the relationship between perceived discrimination and university students' mental health, and thus make an important contribution to identifying ways in which these students' experiences can be enhanced in the face of adverse life events.

\section{DATA AVAILABILITY STATEMENT}

The raw data supporting the conclusion of this article will be made available by the authors, without undue reservation.

\section{ETHICS STATEMENT}

The studies involving human participants were reviewed and approved by University of Western Australia Human Research

\section{REFERENCES}

American Psychiatric Association (2013). Diagnostic and Statistical Manual of Mental Disorders $\left(D S M-5^{\circledR}\right)$. 5th ed. Arlington, VA: American Psychiatric Association (APA).

American Psychological Association (2019). Discrimination: What it Is, and How to Cope. Available at: https://www.apa.org/topics/racism-bias-discrimination/ types-stress (Accessed May 7, 2021).

Assari, S., Moazen-Zadeh, E., Caldwell, C. H., and Zimmerman, M. A. (2017). Racial Discrimination during Adolescence Predicts Mental Health Deterioration in Adulthood: Gender Differences Among Blacks. Front. Public Health 5, 104-110. doi:10.3389/fpubh.2017.00104

Australian Government (2019). "Department of Education, Skills and Employment," in International Students Data. Available at: https:// internationaleducation.gov.au/research/International-Student-Data/Pages/ InternationalStudentData2019.aspx\#Pivot_Table (Accessed January 1, 2021).

Australian Human Rights Commission (2021). Racial Discrimination. Available at: https://guides.library.uwa.edu.au/apa/formats_web_sources (Accessed December 11, 2021)

Barlow, D. H. (1991). Disorders of Emotion. Psychol. Inq. 2 (1), 58-71. doi:10.1207/ s15327965pli0201_15

Barrable, A., Papadatou-Pastou, M., and Tzotzoli, P. (2018). Supporting Mental Health, Wellbeing and Study Skills in Higher Education: an Online Intervention System. Int. J. Ment. Health Syst. 12 (1), 54-59. doi:10.1186/ s13033-018-0233-z

Bender, M., van Osch, Y., Sleegers, W., and Ye, M. (2019). Social Support Benefits Psychological Adjustment of International Students: Evidence from a MetaAnalysis. J. Cross-Cultural Psychol. 50 (7), 827-847. doi:10.1177/0022022119861151

Bewick, B., Koutsopoulou, G., Miles, J., Slaa, E., and Barkham, M. (2010). Changes in Undergraduate Students' Psychological Well-being as They Progress through university. Stud. higher Educ. 35 (6), 633-645. doi:10.1080/03075070903216643

Bhochhibhoya, A., Dong, Y., and Branscum, P. (2017). Sources of Social Support Among International College Students in the United States. J. Int. Students 7 (3), 671-686. doi:10.5281/zenodo.570032

Blodorn, A., Major, B., and Kaiser, C. (2016). Perceived Discrimination and Poor Health: Accounting for Self-Blame Complicates a Well-Established Relationship. Soc. Sci. Med. 153, 27-34. doi:10.1016/j.socscimed.2016.01.053
Ethics Committee. The patients/participants provided their written informed consent to participate in this study.

\section{AUTHOR CONTRIBUTIONS}

JZ-Conceptualization; Data curation; Formal analysis; Investigation; Methodology; Project administration; Validation; Visualization; Writing_original draft; Writing_review editing; Writing-review editing EC-Conceptualization; Data curation; Formal analysis; Investigation; Methodology; Project administration; Supervision; Validation; Visualization; Writing-original draft; Writing-review editing SH-Conceptualization; Methodology; Supervision; Writing-review editing DL-Conceptualization; Methodology; Supervision; Writing-review editing.

\section{SUPPLEMENTARY MATERIAL}

The Supplementary Material for this article can be found online at: https://www.frontiersin.org/articles/10.3389/feduc.2022.726614/ full\#supplementary-material

Bolton, R. (2020). "Unis Fear $\$ 12 b$ Hit as Chinese Students Stay home," in Financial Review. Available at: https://www.afr.com/work-and-careers/ education/unis-fear-12b-hit-as-chinese-students-stay-home-20200428-p54nu7 (Accessed April 28, 2021).

Browne, V., Munro, J., and Cass, J. (2017). The Mental Health of Australian University Students. J. Aust. New Zealand Student Serv. Assoc 25 (2). Available at:https://research-repository.griffith.edu.au/bitstream/handle/10072/393061/ Munro261929Published.pdf?sequence=3doi:10.30688/janzssa.2017.16

Chang, J., Yuan, Y., and Wang, D. (2020). Mental Health Status and its Influencing Factors Among College Students during the Epidemic of COVID-19. Nan Fang Yi Ke Da Xue Xue Bao 40 (2), 171-176. doi:10.12122/j.issn.1673-4254.2020. 02.06

Charlton, E. (2020). Unemployment Worries Spike Around the World as Coronavirus Remains Top Global Concern. World Economic Forum. Available at: https://www.weforum.org/agenda/2020/06/coronavirusunemployment-top-global-worries-ipsos/(Accessed April 1, 2021).

Chen, J. A., Zhang, E., and Liu, C. H. (2020). Potential Impact of COVID-19Related Racial Discrimination on the Health of Asian Americans. Am. J. Public Health (Ajph) 110 (11), 1624-1627. doi:10.2105/ajph.2020. 305858

Cohen, S. (2004). Social Relationships and Health. Am. Psychol. 59 (8), 676-684. doi:10.1037/0003-066X.59.8.676

Copeland, W. E., McGinnis, E., Bai, Y., Adams, Z., Nardone, H., Devadanam, V., et al. (2021). Impact of COVID-19 Pandemic on College Student Mental Health and Wellness. J. Am. Acad. Child Adolesc. Psychiatry 60 (1), 134-141. doi:10. 1016/j.jaac.2020.08.466

Daniel, J. (2020). Education and the COVID-19 Pandemic. Prospects 49 (1), 91-96. doi:10.1007/s11125-020-09464-3

Department of Education, Skills and Employment (2021). Australian Strategy for International Education 2021-2030. Available at: https://www.dese.gov.au/ australian-strategy-international-education-2021-2030 (Accessed December 17, 2021).

Devakumar, D., Shannon, G., Bhopal, S. S., and Abubakar, I. (2020). Racism and Discrimination in COVID-19 Responses. Lancet 395 (10231), 1194. doi:10. 1016/S0140-6736(20)30792-3

Downs, A., Boucher, L. A., Campbell, D. G., and Dasse, M. (2013). Development and Initial Validation of the Symptoms and Assets Screening Scale. J. Am. Coll. Health 61 (3), 164-174. doi:10.1080/07448481.2013.773902 
Downs, A., Boucher, L. A., Campbell, D. G., and Polyakov, A. (2017). Using the WHO-5 Well-Being Index to Identify College Students at Risk for Mental Health Problems. J. Coll. Student Development 58 (1), 113-117. doi:10.1353/csd. 2017.0008

Randall, J., and Jung, H. J. (2018). "The SAGE Encyclopedia of Educational Research, Measurement, and Evaluation," in The SAGE Encyclopedia of Educational Research, Measurement, and Evaluation. Editor B. B. Frey (Thousand Oaks: Sage Publications), 365-370. doi:10.4135/9781506326139

Frey, B. B., and Kan, M. P. H. (2018). "The SAGE Encyclopedia of Educational Research, Measurement, and Evaluation," in The SAGE Encyclopedia of Educational Research, Measurement, and Evaluation. Editor B. B. Frey (Sage Publications), 649-653. doi:10.4135/9781506326139

Fu, W., Yan, S., Zong, Q., Anderson-Luxford, D., Song, X., Lv, Z., et al. (2021). Mental Health of College Students during the COVID-19 Epidemic in China. J. Affect Disord. 280, 7-10. doi:10.1016/j.jad.2020.11.032

Hatcher, L. (1994). A Step-by-step Approach to Using the SAS ${ }^{\circledR}$ System for Factor Analysis and Structural Equation Modeling. Cary: SAS Institute, Inc.

He, J., He, L., Zhou, W., Nie, X., and He, M. (2020). Discrimination and Social Exclusion in the Outbreak of COVID-19. Int. J. Environ. Res. Public Health 17 (8), 2933. doi:10.3390/ijerph17082933

Hechanova-Alampay, R., Beehr, T. A., Christiansen, N. D., and Van Horn, R. K. (2002). Adjustment and Strain Among Domestic and International Student Sojourners. Sch. Psychol. Int. 23 (4), 458-474. doi:10.1177/0143034302234007

Holm, S. (1979). A Simple Sequentially Rejective Multiple Test Procedure. Scand. J. Stat. 6 (2), 65-70. Available at: https://www.jstor.org/stable/pdf/4615733.pdf? refreqid=excelsior\%3A92782c17a9b56484d83b3a9784b45094.

Hooper, D., Coughlan, J., and Mullen, M. R. (2008). Structural Equation Modelling: Guidelines for Determining Model Fit. J. Business Res. Methods 6, 53-60. doi:10. 21427/D7CF7R

Horigian, V. E., Schmidt, R. D., and Feaster, D. J. (2020). Loneliness, Mental Health, and Substance Use Among US Young Adults during COVID-19. J. Psychoactive Drugs 53 (1), 1-9. doi:10.1080/02791072.2020.1836435

Hoyle, R. H. (1995). “The Structural Equation Modeling Approach: Basic Concepts and Fundamental Issues," in Structural Equation Modeling: Concepts, Issues, and Applications. Editor R. H. Hoyle (Thousand Oaks: Sage Publications, Inc), 1-15.

Huckins, J. F., daSilva, A. W., Wang, W., Hedlund, E., Rogers, C., Nepal, S. K., et al. (2020). Mental Health and Behavior of College Students during the Early Phases of the COVID-19 Pandemic: Longitudinal Smartphone and Ecological Momentary Assessment Study. J. Med. Internet Res. 22 (6), e20185. doi:10.2196/ 20185

Hughes, C. (2021). Education export Income from Chinese Students in Australia FY 2014-2019. Available at: https://www.statista.com/statistics/1086549/ australia-education-export-income-chinese-students/.

Hurley, P., and Van Dyke, N. (2020). Australian Investment in Education: Higher Education. Melbourne: Mitchell Institute. Available at: https:/www.vu.edu.au/ sites/default/files/australian-investment-in-education-higher-education-mitchellinstitute.pdf?fbclid=IwAR38CBffBIK8N8XEWPBSXFkP0M2jv5GRoAkD5B8sXo0Y1zh-OsP863GIeY.

Ioannou, M., Kassianos, A. P., and Symeou, M. (2019). Coping with Depressive Symptoms in Young Adults: Perceived Social Support Protects against Depressive Symptoms Only under Moderate Levels of Stress. Front. Psychol. 9, 2780. doi:10.3389/fpsyg.2018.02780

Kaiser, H. F. (1960). The Application of Electronic Computers to Factor Analysis. Educ. Psychol. Meas. 20 (1), 141-151. doi:10.1177/001316446002000116

Kecojevic, A., Basch, C. H., Sullivan, M., and Davi, N. K. (2020). The Impact of the COVID-19 Epidemic on Mental Health of Undergraduate Students in New Jersey, Cross-Sectional Study. PLoS One 15 (9), e0239696. doi:10.1371/journal. pone.0239696

Khawaja, N. G., and Dempsey, J. (2008). A Comparison of International and Domestic Tertiary Students in Australia. Aust. J. Guid. Couns. 18 (1), 30-46. doi:10.1375/ajgc.18.1.30

Kline, R. B. (2016). Methodology in the Social sciences.Principles and Practice of Structural Equation Modeling. 4th ed. New York: Guilford Press.

Krieger, T., Zimmermann, J., Huffziger, S., Ubl, B., Diener, C., Kuehner, C., et al. (2013). Measuring Depression with a Well-Being index: Further Evidence for the Validity of the WHO Well-Being Index (WHO-5) as a Measure of the Severity of Depression. J. Affect Disord. 156, 240-244. doi:10.1016/j.jad.2013.12.015
Kroenke, K., and Spitzer, R. L. (2002). The PHQ-9: A New Depression Diagnostic and Severity Measure. Psychiatr. Ann. 32 (9), 509-515. doi:10.3928/0048-571320020901-06

Lee, E. H., Moon, S. H., Cho, M. S., Park, E. S., Kim, S. Y., Han, J. S., et al. (2019), The 21-Item and 12-item Versions of the Depression Anxiety Stress Scales: Psychometric Evaluation in a Korean Population. Asian Nurs. Res. (Korean Soc. Nurs. Sci. 13 (1), 30-37. doi:10.1016/j.anr.2018.11.006

Lee, S. A. (2020). Coronavirus Anxiety Scale: a Brief Mental Health Screener for COVID-19 Related Anxiety. Death Stud. 44 (7), 393-401. doi:10.1080/ 07481187.2020.1748481

Lewis, T. T., Williams, D. R., Tamene, M., and Clark, C. R. (2014). Self-reported Experiences of Discrimination and Cardiovascular Disease. Curr. Cardiovasc. Risk Rep. 8 (1), 365-415. doi:10.1007/s12170-013-0365-2

Li, H. Y., Cao, H., Leung, D. Y. P., and Mak, Y. W. (2020a). The Psychological Impacts of a COVID-19 Outbreak on College Students in China: A Longitudinal Study. Int. J. Environ. Res. Public Health 17 (11), 1-11. doi:10. 3390/ijerph17113933

Li, Y., Zhao, J., Ma, Z., Mcreynolds, L. S., Lin, D., Chen, Z., et al. (2020b). Mental Health Among College Students during the COVID-19 Pandemic in China: A 2-wave Longitudinal Survey. J. Affect Disord. 281, 597-604. doi:10.1016/j.jad. 2020.11.109

Llewellyn, E. v. Z., Rothmann, S., and Zondervan-Zwijnenburg, M. A. (2021). Longitudinal Trajectories of Study Resources and Mental Gealth before and during the COVID-19 Lockdown: a Brief Report. Front. Psychol. 12, 633533. doi:10.3389/fpsyg.2021.633533

Lovibond, S. H., and Lovibond, P. F. (1995). Manual for the Depression Anxiety Stress Scales. 2nd. Sydney: Psychology Foundation. Available at: https:// comorbidityguidelines.org.au/appendices/appendix-l-depression-anxiety-stressscale-dass-21.

Lovibond, S. H., and Lovibond, P. F. (1993). Manual for the Depression Anxiety Stress Scales (DASS). Sydney: Psychology Foundation Monograph. University of New South Wales.

Ma, Z., Zhao, J., Li, Y., Chen, D., Wang, T., Zhang, Z., et al. (2020). Mental Health Problems and Correlates Among 746217 College Students during the Coronavirus Disease 2019 Outbreak in China. Epidemiol. Psychiatr. Sci. 29, e181. doi:10.1017/S2045796020000931

Menard, S. (2012). "Path Analysis," in Encyclopedia of Research Design. Editor N. J. Salkind (Thousand Oaks : Sage Publications), 1019-1022. doi:10.4135/ 9781412961288.n308

Messick, S. (1989). "Validity," in Educational Measurement. Editor R. L. Linn. 3rd Edition (American Council on Education/Macmillan), 13-103.

Messick, S. (1995). Validity of Psychological Assessment: Validation of Inferences from Persons' Responses and Performances as Scientific Inquiry into Score Meaning. Am. Psychol. 50 (9), 741-749. doi:10.1037/0003-066X.50.9.741

Muñoz-Bermejo, L., Adsuar, J. C., Postigo-Mota, S., Casado-Verdejo, I., de MeloTavares, C. M., Garcia-Gordillo, M. Á., et al. (2020). Relationship of Perceived Social Support with Mental Health in Older Caregivers. Ijerph 17, 3886-3913. doi:10.3390/ijerph17113886

Noh, S., Kaspar, V., and Wickrama, K. A. (2007). Overt and Subtle Racial Discrimination and Mental Health: Preliminary Findings for Korean Immigrants. Am. J. Public Health 97 (7), 1269-1274. doi:10.2105/ajph.2005. 085316

Osman, A., Wong, J. L., Bagge, C. L., Freedenthal, S., Gutierrez, P. M., and Lozano, G. (2012). The Depression Anxiety Stress Scales-21 (DASS-21): Further Examination of Dimensions, Scale Reliability, and Correlates. J. Clin. Psychol. 68 (12), 1322-1338. doi:10.1002/jclp.21908

Paradies, Y. (2006). A Systematic Review of Empirical Research on SelfReported Racism and Health. Int. J. Epidemiol. 35 (4), 888-901. doi:10. 1093/ije/dyl056

Pascoe, E. A., and Smart Richman, L. (2009). Perceived Discrimination and Health: A Meta-Analytic Review. Psychol. Bull. 135 (4), 531-554. doi:10.1037/a0016059

Poyrazli, S., and Lopez, M. D. (2007). An Exploratory Study of Perceived Discrimination and Homesickness: a Comparison of International Students and American Students. J. Psychol. 141 (3), 263-280. doi:10.3200/JRLP.141.3. 263-280

Revicki, D. A., Cook, K. F., Amtmann, D., Harnam, N., Chen, W. H., and Keefe, F. J. (2014). Exploratory and Confirmatory Factor Analysis of the PROMIS Pain Quality Item Bank. Qual. Life Res. 23 (1), 245-255. doi:10.1007/s11136-013-0467-9 
Sandell, E. J., and Tupy, S. J. (2015). Where Cultural Competency Begins: Changes in Undergraduate Students' Intercultural Competency. Int. J. Teach. Learn. Higher Education 27 (3), 364-381. Available at: https://files.eric.ed.gov/fulltext/ EJ1093756.pdf.

Sawir, E., Marginson, S., Deumert, A., Nyland, C., and Ramia, G. (2008). Loneliness and International Students: An Australian Study. J. Stud. Int. Education 12 (2), 148-180. doi:10.1177/1028315307299699

Schulz, A. J., Gravlee, C. C., Williams, D. R., Israel, B. A., Mentz, G., and Rowe, Z. (2006). Discrimination, Symptoms of Depression, and Self-Rated Health Among African American Women in detroit: Results from a Longitudinal Analysis. Am. J. Public Health 96 (7), 1265-1270. doi:10.2105/ajph.2005.064543

Science Daily (2020). COVID-related Discrimination Disproportionately Impacts Racial Minorities, Study Shows: Discrimination against People Perceived to Have COVID-19 Increased from March to April 2020. Science Daily. Available at: https:// www.sciencedaily.com/releases/2020/07/200707113208.htm (Accessed April 5, 2021).

Spitzer, R. L., Kroenke, K., Williams, J. B., and Löwe, B. (2006). A Brief Measure for Assessing Generalized Anxiety Disorder: The GAD-7. Arch. Intern. Med. 166 (10), 1092-1097. doi:10.1001/archinte.166.10.1092

Sun, X., Hall, G. C. N., DeGarmo, D. S., Chain, J., and Fong, M. C. (2021). A Longitudinal Investigation of Discrimination and Mental Health in Chinese International Students: The Role of Social Connectedness. J. Cross-Cultural Psychol. 52 (1), 61-77. doi:10.1177/0022022120979625

Tabachnick, B., and Fidell, L. (2013). Using Multivariate Statistics. 6th ed. Boston: Pearson Education.

Tsai, P.-C., and Wei, M. (2018). Racial Discrimination and Experience of New Possibilities Among Chinese International Students. Couns. Psychol. 46 (3), 351-378. doi:10.1177/0011000018761892

University of Queensland (2021). Inclusion Online Training Modules. Available online: https://staff.uq.edu.au/information-and-services/human-resources/ diversity-and-inclusion/diversity-and-inclusion-programs-and-training/inclusiononline-training-modules.

University of Sydney (2021). National Centre for Cultural Competence Workshops. Available online: https://www.sydney.edu.au/nccc/training-andresources/workshops.html.

van Zyl, L. E., Rothmann, S., and Zondervan-Zwijnenburg, M. A. J. (2021). Longitudinal Trajectories of Study Characteristics and Mental Health before and during the COVID-19 Lockdown. Front. Psychol. 12 (349), 1-13. doi:10. 3389/fpsyg.2021.633533

Wang, C., and Zhao, H. (2020). The Impact of COVID-19 on Anxiety in Chinese university Students. Front. Psychol. 11, 1168. doi:10.3389/fpsyg. 2020.01168

Ward, J. B., Feinstein, L., Vines, A. I., Robinson, W. R., Haan, M. N., and Aiello, A. E. (2019). Perceived Discrimination and Depressive Symptoms Among US Latinos: The Modifying Role of Educational Attainment. Ethn. Health 24 (3), 271-286. doi:10.1080/13557858.2017.1315378

Wathelet, M., Duhem, S., Vaiva, G., Baubet, T., Habran, E., Veerapa, E., et al. (2020). Factors Associated with Mental Health Disorders Among university Students in France Confined during the COVID-19 Pandemic. JAMA Netw. Open 3 (10), e2025591. doi:10.1001/jamanetworkopen.2020.25591

Wei, M., Liang, Y.-S., Du, Y., Botello, R., and Li, C.-I. (2015). Moderating Effects of Perceived Language Discrimination on Mental Health Outcomes Among
Chinese International Students. Asian Am. J. Psychol. 6 (3), 213-222. doi:10. 1037/aap0000021

White, R. G., and Van Der Boor, C. (2020). Impact of the COVID-19 Pandemic and Initial Period of Lockdown on the Mental Health and Well-Being of Adults in the UK. BJPsych Open 6 (5), e90. doi:10.1192/bjo.2020.79

World Health Organization (2022). Mental Health \& COVID-19. Available at: https://www.who.int/teams/mental-health-and-substance-use/covid-19 (Accessed March 20, 2021).

World Health Organization (1998). Wellbeing Measures in Primary Health Care/ the Depcare Project. WHO Regional Office for Europe: Copenhagen, Demark. Available at: https://www.euro.who.int/_data/assets/pdf_file/0016/130750/ E60246.pdf (Accessed February 12-13, 1998).

Xu, J., Ou, J., Luo, S., Wang, Z., Chang, E., Novak, C., et al. (2020). Perceived Social Support Protects Lonely People against COVID-19 Anxiety: A Three-Wave Longitudinal Study in China. Front. Psychol. 11, 566965. doi:10.3389/fpsyg. 2020.566965

Yeh, C. J., and Inose, M. (2003). International Students' Reported English Fluency, Social Support Satisfaction, and Social Connectedness as Predictors of Acculturative Stress. Counselling Psychol. Q. 16 (1), 15-28. doi:10.1080/ 0951507031000114058

Zhang, Y. (2012). An Examination of Acculturative Stress, Perceived Social Support and Depression Among Chinese International Students. New York: ProQuest Dissertations Publishing. Available at: https://surface.syr.edu/cgi/viewcontent. cgi? article $=1002 \&$ context $=$ cfs_thesis.

Zimet, G. D., Dahlem, N. W., Zimet, S. G., and Farley, G. K. (1988). The Multidimensional Scale of Perceived Social Support. J. Personal. Assess. 52 (1), 30-41. doi:10.1207/s15327752jpa5201_2

Zung, W. W. (1971). A Rating Instrument for Anxiety Disorders. Psychosomatics 12 (6), 371-379. doi:10.1016/S0033-3182(71)71479-0

Zung, W. W., Richards, C. B., and Short, M. J. (1965). Self-rating Depression Scale in an Outpatient Clinic. Further Validation of the SDS. Arch. Gen. Psychiatry 13 (1), 508-515. doi:10.1001/archpsyc. 1965.0172031006500810.1001/archpsyc. 1965.01730060026004

Conflict of Interest: The authors declare that the research was conducted in the absence of any commercial or financial relationships that could be construed as a potential conflict of interest.

Publisher's Note: All claims expressed in this article are solely those of the authors and do not necessarily represent those of their affiliated organizations, or those of the publisher, the editors and the reviewers. Any product that may be evaluated in this article, or claim that may be made by its manufacturer, is not guaranteed or endorsed by the publisher.

Copyright $\odot 2022$ Zhao, Chapman, Houghton and Lawrence. This is an open-access article distributed under the terms of the Creative Commons Attribution License (CC $B Y)$. The use, distribution or reproduction in other forums is permitted, provided the original author(s) and the copyright owner(s) are credited and that the original publication in this journal is cited, in accordance with accepted academic practice. No use, distribution or reproduction is permitted which does not comply with these terms. 